\title{
EDITORIAL
}

\section{The challenge of evaluating the effectiveness of treatments for deliberate self-harm ${ }^{1}$}

\begin{abstract}
Deliberate self-harm (DSH) is the most important factor associated with risk of suicide. It also poses a considerable burden on health and social services. Repetition of DSH after hospital presentation is common, with most studies reporting between 12 and $25 \%$ of patients repeating within a year and again presenting to hospital (Owens et al. 2002) and many more being involved in repeat episodes which do not bring them to clinical attention (Guthrie et al. 2001). Repetition itself increases the risk of a fatal outcome (Sakinofsky, 2000). The results of both psychosocial and pharmacological interventions to prevent repetition have been fairly disappointing (Hawton et al. 1998, 2000), although the findings of treatment trials have not all been negative. Dialectical behaviour therapy had a substantial initial impact on repetition of self-harm, although this did not persist in a treatment study of female patients with borderline personality disorders (Linehan et al. 1991) and depot flupenthixol reduced repetition in frequent self-harmers (Montgomery, 1987). A recent trial of brief psychotherapy was more effective than treatment as usual (Guthrie et al. 2001) and a meta-analysis of trials of problem-solving therapy suggested beneficial effects for depression, hopelessness and specific problems (Townsend et al. 2001).
\end{abstract}

\section{THE NEED FOR LARGE CLINICALLY RELEVANT TRIALS}

One of the main drawbacks of most treatment studies to date involving DSH patients has been their relatively small size and hence limited power (Hawton et al. 1998). Given the large number of DSH patients presenting to general hospitals (Kapur \& House, 1998; Wilkinson et al. 2002) and the need to target this population as part of national suicide prevention strategies, for example the Department of Health in the UK in 2002, there is a need for robust information from large trials of pragmatic treatments suitable for application in NHS settings. Following a promising pilot study (Evans et al. 1999), in this issue Tyrer and colleagues (2003a) have taken up the challenge and conducted a large multi-centre trial (the POPMACT study) to evaluate a novel treatment in DSH patients.

\section{PATIENT SUBGROUPS AND TARGETED TREATMENTS}

$\mathrm{DSH}$ is not a diagnosis but a behaviour and as such is seen in a diverse range of patients. This includes patients with and without mental illness, a wide range of psychosocial problems and substance misuse. Also, while some patients will carry out a single episode of self-harm, many will repeat, frequently in some cases (Bancroft \& Marsack, 1977). Although the majority of patients are young adults, the behaviour is seen across the age spectrum from late childhood to extreme old age. Each of these groups presents with their own needs and management challenges.

While the POPMACT study focused on repeaters of DSH (at least two episodes of self-harm), it is clear that these still represent a heterogeneous group. Even within this study, patient characteristics differ markedly between centres (Tyrer et al. 2003 b). The exclusion of patients with major alcohol or drug misuse problems is understandable for pragmatic reasons, however, in view of the importance of substance misuse in risk of both DSH and suicide (Inskip et al. 1998; Murphy, 2000), it highlights the need to develop more effective services and treatments for this group of patients.

\footnotetext{
${ }^{1}$ Address for correspondence: Professor Keith Hawton, Centre for Suicide Research, University Department of Psychiatry, Warneford Hospital, Headington, Oxford OX3 7JX.
} 
Even after their exclusion, the number of further patients excluded from the POPMACT study was large, refusal or not attending the initial assessment being the most frequent reasons (Tyrer et al. $2003 \mathrm{~b}$ ). This is probably inevitable when targeting a patient population prone to low rates of compliance with aftercare (Crawford \& Wessely, 2000).

The experimental treatment in the POPMACT trial, combining both brief psychological therapy and a manual, was compared with treatment as usual. Given the relatively high proportion of patients in the experimental group who failed to attend any treatment sessions $(38 \%)$, the role of the treatment manual is particularly important. Unfortunately, no data are available on the extent to which it was actually used. The fact that it was 70 pages long raises unanswered questions about how attractive it might be to this patient population.

\section{COMPARISON WITH TREATMENT AS USUAL}

It is understandable that in the POPMACT trial a treatment as usual (TAU) control condition was used. This has been the case in several previous trials in this population (Hawton et al. 1998), however the use of TAU raises several issues. It is clear that it will vary greatly from service to service, as the authors and others (Spirito et al. 2002) have highlighted. There were marked variations in service practice between the centres in this study (Tyrer et al. 2003 b), perhaps reflecting differences in patient populations, but, more likely, local clinical preferences. Use of multiple centres increases the generalizability of the study findings but as the authors point out the clinical effectiveness of TAU may also vary. Due to the nature of the TAU it was not possible to know the extent of compliance with care, which is another drawback of this type of control. Future trials need to address these issues.

\section{EVALUATION OF OUTCOMES}

In order to be sensitive to the variety of problems experienced by DSH patients, a range of measures needs to be used in evaluating outcome following treatment, as was the case in the POPMACT study. Thus, the measures included both the primary outcome of further repetition of DSH and several secondary outcomes (measures of mood, social and global functioning, thinking styles, and quality of life, plus costs and cost effectiveness). Importantly, repetition of DSH included acts which did not lead to medical treatment - this was more than half of the repeat acts. In the trial by Guthrie and colleagues (2001), for example, this was crucial to their obtaining a statistically significant difference between their experimental and control treatment condition.

\section{COST-EFFECTIVE ANALYSES}

The cost effectiveness analysis conducted as an integral part of this study and presented in this issue (Byford et al. 2003), is a valuable addition to the literature on the importance of costeffectiveness analyses of psychological interventions in mental health. The POPMACT study correctly takes a broad economic perspective despite the uncertainties this introduces into the analysis, which are acknowledged and the assumptions tested in the sensitivity analyses (Drummond et al. 1998). All decisions about the cost-effectiveness of interventions are based on uncertain information of the inputs into an economic model, such as clinical effects, health-related quality of life and use of resources (Claxton et al. 2002). However, the conclusion of the cost effectiveness analysis of the POPMACT trial that 'based on the evidence currently available ... to continue funding current practice has less than a $10 \%$ chance of being the correct decision in terms of cost effectiveness' (Byford et al. 2003) requires some qualification.

\section{THEORETICAL MODELS AND CLINICAL UTILITY}

While there may be a need for clinical readers to consider the health policy aspects of decisionmaking approaches in whether or not to adopt a new intervention, there is also a need for policy makers to consider the clinical reality behind the economic model. DSH is a chronic, often recurrent 
behaviour about which we know very little in terms of the long-term costs incurred to the individual the health service or society. There is a need for good cost-of-illness data in DSH patients, to explore the long-term costs, based on epidemiological trends. This would aid prediction of how changing patterns might affect service utilization, as well as clarifying the most important cost components in this patient group. Without this, it is difficult to place the cost effectiveness evaluation of the POPMACT study into context, both in terms of evaluating the magnitude of the incremental cost effectiveness ratio calculated or applying these results to an unselected patient group.

\section{COSTS OF DELIBERATE SELF-HARM}

We have some information about the short-term costs involved in DSH management, in terms of admission costs for DSH (Yeo, 1993; Kapur et al. 2002) and the relative costs of managing tricyclic antidepressant and SSRI overdoses (Ramchandani et al. 2000). There are also details about the service utilization patterns of DSH patients that suggest that the majority have contact with health services in the year prior to and after DSH, but that the presence of a psychotic illness, mood disorder or personality disorder is a significant predictor of health care contacts in the 30 days following DSH (Suominen et al. 2002). However, there is little information on the breadth of services used, which the POPMACT study helps elucidate, or the effect of the patient's behaviour on family and carers, in terms of quality of life and lost resources. At present it is also difficult to determine how much of the costs of service provision are due directly to DSH and how much may be attributed to aspects of any underlying mental disorder, which would continue to be incurred even if further presentations for DSH were eradicated.

In the same way that clinicians extrapolate from the clinical efficacy data of randomized controlled trials to decide on the likely effectiveness of a particular intervention in a broader patient sample, so too policy makers need to consider the whole patient population that would be affected by adopting a new intervention and how the differences between the trial sample and population may alter the probabilities of cost effectiveness. Thus, the patients excluded from studies such as the POPMACT trial need to be considered in terms of their potential for service utilization, given we know nothing of the effectiveness of the intervention in these groups.

\section{CONCLUSIONS}

The study of Tyrer and colleagues has advanced the evaluative approaches of DSH patients, particularly in terms of measurement of healthcare costs. However, the clinically negative result of this trial is disappointing. The authors discuss various possible explanations for this. One is left wondering, however, whether more intensive therapies are required to help many repeaters of DSH and whether further delineation of subgroups of patients and treatments (both psychosocial and pharmacological) is needed. A more pessimistic interpretation of the findings of the POPMACT trial and previous research in this area would be that the problems faced by people who repeat DSH may not be altered greatly by whatever we do. We do not ourselves subscribe to the nihilistic view but clearly our endeavours in this area have a long way to go.

KEITH HAWTON AND JULIA SINCLAIR

Keith Hawton was a member of the Steering Committee for the POPMACT trial.

\section{REFERENCES}

Bancroft, J. \& Marsack, P. (1977). The repetitiveness of selfpoisoning and self-injury. British Journal of Psychiatry 131, 394-399.

Byford, S., Knapp, M., Greenshields, J., Ukoumunne, O. C., Jones, V., Thompson, S., Davidson, K., Schmidt, U., Tyrer, P. Catalan, J., Airlie, J., Baxter, S., Byrne, G., Cameron, S.,
Caplan, R., Cooper, S., Ferguson, B., Fowler, L. \& Freeman, C. (2003). Cost-effectiveness of brief cognitive behaviour therapy versus treatment as usual in recurrent deliberate selfharm: a decision-making approach. Psychological Medicine 33, 977-986.

Claxton, K., Sculpher, M. \& Drummond, M. (2002). A rational framework for decision making by the National Institute For Clinical Excellence (NICE). Lancet 360, 711-715. 
Crawford, M. J. \& Wessely, S. (2000). The management of patients following deliberate self-harm - what happens to those discharged from hospital to GP care? Primary Care Psychiatry 6, 61-65.

Drummond, M., O'Brien, B., Stoddard, G. \& Torrance, G. (1998). Methods for the Economic Evaluation of Health Care Programmes, 2nd edn. Oxford University Press: Oxford.

Evans, K., Tyrer, P., Catalan, J., Schmidt, U., Davidson, K., Dent, J., Tata, P., Thornton, S., Barber, J. \& Thompson, S. (1999). Manualassisted cognitive-behaviour therapy (MACT): a randomized controlled trial of a brief intervention with bibliotherapy in the treatment of recurrent deliberate self-harm Psychological Medicine 29, 19-25.

Guthrie, E., Kapur, N., Mackway-Jones, K., Chew-Graham, C., Moorey, J., Mendel, E., Marino-Francis, F., Sanderson, S., Turpin, C., Boddy, G. \& Tomenson, B. (2001). Randomised controlled trial of brief psychological intervention after deliberate self poisoning. British Medical Journal 323, 135-137.

Hawton, K., Arensman, E., Townsend, E., Bremner, S., Feldman, E., Goldney, R., Gunnell, D., Hazell, P., Van Heeringen, C., House, A., Owens, D., Sakinofsky, I. \& Traskman-Bendz, L. (1998). Deliberate self-harm: systematic review of efficacy of psychosocial and pharmacological treatments in preventing repetition. British Medical Journal 317, 441-447.

Hawton, K., Townsend, E., Arensman, E., Gunnell, D., Hazell, P., Van Heeringen, K. \& House, A. (2000). Psychosocial and pharmacological treatments for deliberate self-harm. In The Cochrane Review, Library Issue 3, vol. 3. Update Software: Oxford.

Inskip, H. M., Harris, E. C. \& Barraclough, B. (1998). Lifetime risk of suicide for affective disorder, alcoholism and schizophrenia. British Jounal of Psychiatry 172, 35-37.

Kapur, N. \& House, A. (1998). Against a high-risk strategy in the prevention of suicide. Psychiatric Bulletin 22, 534-536.

Kapur, N., House, A., Dodgson, K., May, C., Marshall, S. Tomenson, B. \& Creed, F. (2002). Management and costs of deliberate self-poisoning in the general hospital: a multi-centre study. Journal of Mental Health UK 11, 223-230.

Linehan, M., Armstrong, H. E., Suarez, A., Allmari, D. \& Heard, H. L. (1991). Cognitive behavioral treatment of chronically parasuicidal borderline patients. Archives of General Psychiatry 48, 1060-1064.

Montgomery, S. A. (1987). The psychopharmacology of borderline personality disorders. Acta Psychiatrica Belgica 87, 260-266.

Murphy, G. E. (2000). Psychiatric aspects of suicidal behaviour: substance abuse. In The International Handbook of Suicide and Attempted Suicide (ed. K. Hawton and K. Van Heeringen), pp. 135-146. Wiley: Chichester.
Owens, D., Horrocks, J. \& House, A. (2002). Fatal and nonfatal repetition of self-harm - systematic review. British Journal of Psychiatry 181, 193-199.

Ramchandani, P., Murray, B., Hawton, K. \& House, A. (2000). Deliberate self poisoning with antidepressant drugs: a comparison of the relative hospital costs of cases of overdose of tricyclics with those of selective-serotonin re-uptake inhibitors. Journal of Affective Disorders 60, 97-100.

Sakinofsky, I. (2000). Repetition of suicidal behaviour. In The International Handbook of Suicide and Attempted Suicide (ed. K. Hawton and K. Van Heeringen), pp. 385-404. Wiley: Chichester.

Spirito, A., Stanton, C., Donaldson, D. \& Boergers, J. (2002). Treatment-as-usual for adolescent suicide attempters: implications for the choice of comparison groups in psychotherapy research. Journal of Clinical Child and Adolesent Psychology 31, $41-47$.

Suominen, K. H., Isometsa, E. T., Ostamo, A. I. \& Lonnqvist, J. K. (2002). Health care contacts before and after attempted suicide. Social Psychiatry and Psychiatric Epidemiology 37, 89-94.

Townsend, E., Hawton, K., Altman, D. G., Arensman, E., Gunnell, D., Hazell, P., House, A. \& Van Heeringen, K. (2001). The efficacy of problem-solving treatments after deliberate self-harm: metaanalysis of randomized controlled trials with respect to depression, hopelessness and improvement in problems. Psychological Medicine 31, 979-988.

Tyrer, P., Thompson, S., Schmidt, U., Jones, V., Knapp, M., Davidson, K., Catalan, J., Airlie, J., Baxter, S., Byford, S., Byrne, G., Cameron, S., Caplan, R., Cooper, S., Ferguson, B., Fowler, L., Freeman, C., Frost, S., Godley, J. \& Greenshields, J. $(2003 a)$. Randomized controlled trial of brief cognitive behaviour therapy versus treatment as usual in recurrent deliberate self-harm: the POPMACT study. Psychological Medicine 33, 969-976.

Tyrer, P., Jones, V., Thompson, S., Catalan, J., Schmidt, U., Davidson, K., Knapp, M. \& Ukoumunne, O. (2003b). Service variation in baseline variables and prediciton of risk in a randomised controlled trial of psychological treatment in repeated parasuicide: the POPMACT study. International Journal of Social Psychiatry 49, 58-69.

Wilkinson, S., Taylor, G., Templeton, L., Mistral, W., Salter, E. \& Bennett, P. (2002). Admissions to hospital for deliberate self-harm in England 1995-2000: an analysis of Hospital Episode Statistics. Journal of Public Health Medicine 24, 179-183.

Yeo, H. M. (1993). The cost of treatment of deliberate self-harm. Archives of Emergency Medicine 10, 8-14. 